\title{
PROGRAMA DE REVITALIZACIÓN INTEGRAL DE CENTROS HISTÓRICOS DE IBEROAMÉRICA
}

\section{(HISTORICAL CENTRE REVITALIZATION PROGRAMME IN LATIN-AMERICA)}

M. ${ }^{\text {a }}$ Luisa Cerrillos, Arquitecta

Sociedad Estatal Quinto Centenario ESPAÑA

\section{RESUMEN}

En el presente articulo se expone la actuación que la Agencia Española de Cooperación Internacional y la Comisión Nacional Quinto Centenario vienen desarrollando desde 1982 con un Programa de Revitalización de Centros Históricos en Iberoamérica, entendidos no sólo como "Patrimonio Cultural", sino, desde una óptica de acercamiento real a los problemas, del patrimonio edificado y urbanizado, que resulta prioritario recuperar como "patrimonio social colectivo".

Tres son los objetivos fundamentales del Programa:

- Contribuir efectivamente a la recuperación de los Centros Históricos Iberoamericanos.

- Formación de técnicos experimentados en la resolución de la problemática de los centros urbanos de características histórico-artísticas.

- Explorar conjuntamente, españoles e iberoamericanos, nuevos caminos de entendimiento mutuo, sobre la base de proyectos concretos.

Para la consecución de estos objetivos se han seguido unas lineas de actuación que se comentan ampliamente en el texto, en el que se realiza, asimismo, una pormenorizada exposición de algunas de las intervenciones llevadas a cabo hasta la fecha.

\section{SUMMARY}

This article states that the following action will be taken:

That the Spanish Agency for International Cooperation and the Quincentenary National Commission have been preparing a Historical Revitalization Programme in Latin America since 1982 and that these programmes are not simply to be viewed as "Cultural Heritage" but also as a real attempt to draw closer to problems such as buildings and urban heritage which appear to be of priority for the recovery of the "social collective heritage".

The Programme has three main objectives:

- To effectively contribute to the recovery of Latin American Historical Centres.

- To train technicians with experience in the solving of problems connected with urban centres of historical characteristics.

- For the Spanish and Latin Americans to look together for new paths to enhance mutual understanding using concrete projects.

In order to attain these objectives, guide-lines have been made and these are comprehensively discussed in the text.

The latter also contains a detailed description of some of the interventions carried out up till today.

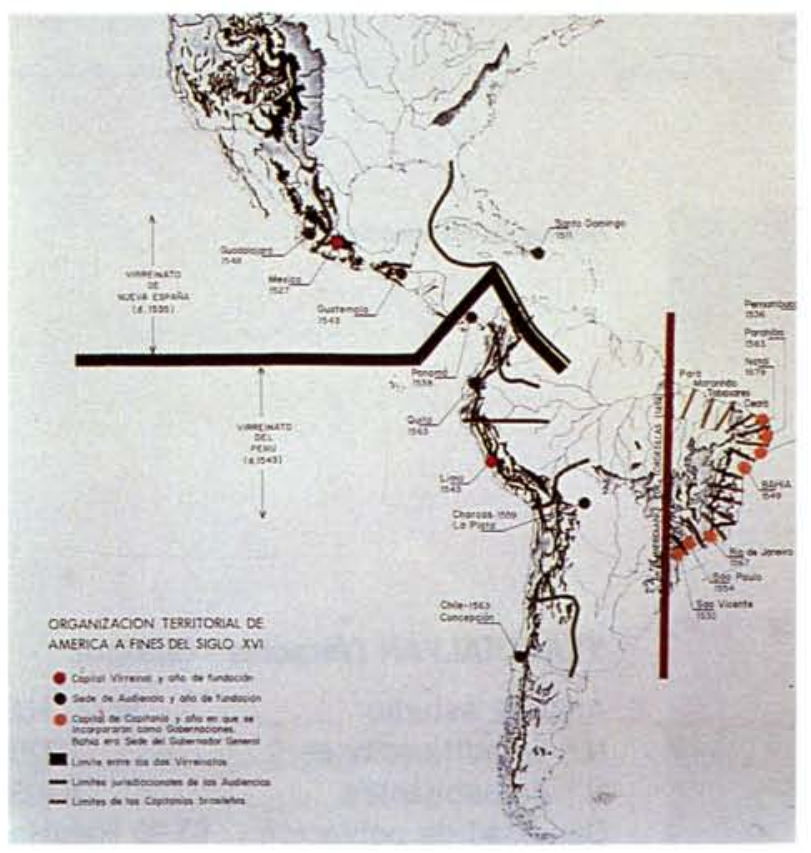

(c) Consejo Superior de Investigaciones Científicas Licencia Creative Commons 3.0 España (by-nc)
La Agencia Española de Cooperación Internacional y la Comisión Nacional Quinto Centenario están promoviendo desde 1982 un programa de revitalización de centros históricos iberoamericanos, planteado desde sus comienzos con tres objetivos básicos:

- El primero y fundamental, contribuir positivamente a la recuperación y conservación de los centros históricos iberoamericanos como patrimonio social colectivo.

- El segundo, la formación y cualificación de los miembros de los equipos redactores con miras a la creación de cuadros de técnicos experimentados en la resolución real de la compleja problemática de la revitalización de los conjuntos urbanos de características histórico-artísticas. 
- El tercero explorar, conjuntamente entre técnicos españoles e iberoamericanos, nuevos caminos de entendimiento y conocimiento mutuos, sobre la base de proyectos concretos y definidos.

Los proyectos desarrollan, a lo largo de su duración (generalmente un año), dos grandes líneas de actuación:

1) La redacción de una normativa urbanistica exhaustiva que contemple, desde los aspectos más generales, la ordenación de los conjuntos históricos (zonificación y usos del suelo, redes de transporte, tránsito, etc...), hasta los aspectos especificos de cada manzana y de cada edificio (volumetria, densidades, niveles de intervención, propuestas de uso, etcétera).

2) La redacción de un programa de "Proyectos de Intervención" que contemple por anualidades y con un criterio selectivo de prioridades aquellos proyectos que, por sus características y repercusión en el conjunto, contribuyan de forma real a la revitalización de la estructura urbana.

El programa deberá canalizar y gestionar los fondos de las distintas Instituciones con capacidad de intervención en los centros históricos hacia aquellos proyectos que cumplan realmente los objetivos propuestos.
El estudio de revitalización establece además la creación permanente de "Oficinas del Centro Histórico" mantenidas por las Instituciones locales y compues. tas por el personal formado a lo largo del trabajo. Estas oficinas tienen como misión principal la redacción, coordinación y dirección de las obras y proyectos propuestos, así como la asesoría ciudadana y el control de la aplicación de la Normativa Urbanística.

En las anualidades siguientes a los estudios de revitalización, la Agencia Española de Cooperación Internacional y la Comisión Nacional Quinto Centenario siguen incorporados a cada proyecto mediante la financiación de obras concretas de las previstas en cada Programa de Intervención, cuyo seguimiento y acompañamiento se lleva a cabo periódicamente por los técnicos españoles.

Hasta el momento se han realizado los siguientes Proyectos de Revitalización:

- TLACOTALPAN (Veracruz - México).

- CIUDAD BOLIVAR (Bolívar - Venezuela).

- JOÃO PESSOA (Paraiba - Brasil).

- PONCE (Puerto Rico).

\section{CARACTERISTICAS GENERALES DE LOS PROYECTOS DE REVITALIZACION REALIZADOS}

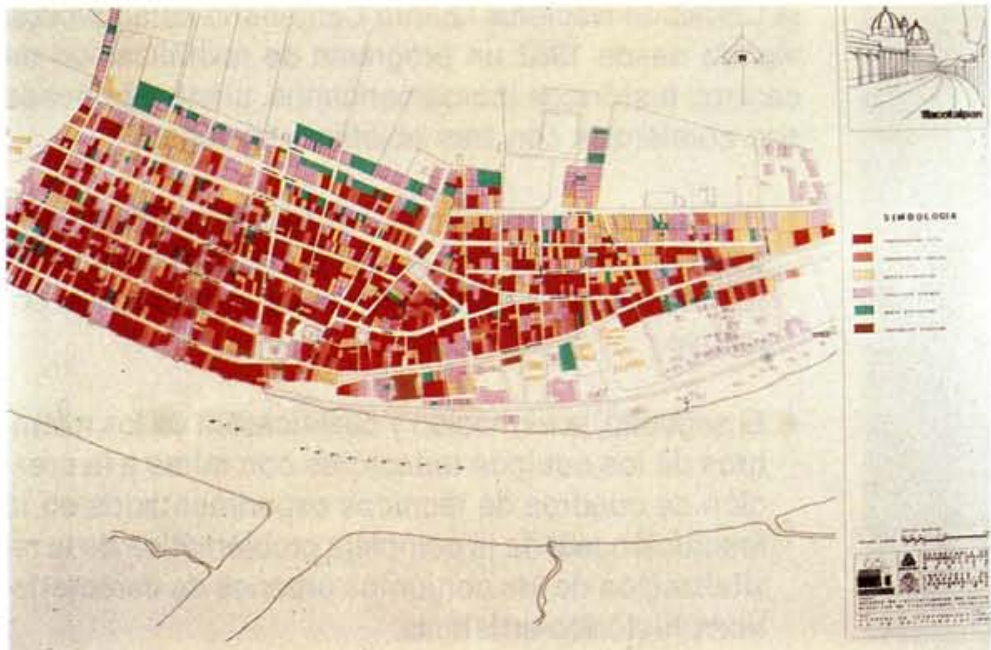

Niveles de intervención

\section{TLACOTALPAN (Veracruz · México):}

Área de estudio $86,23 \mathrm{Ha}$ N. ${ }^{\circ}$ de edificaciones 1.929

N. ${ }^{\circ}$ de habitantes 8.105

Densidad de población .. 93,90 $\mathrm{Hab} / \mathrm{Ha}$ 
La ciudad de Tlacotalpan se funda en 1521, otorgándose como encomienda y estableciéndose su Alcaldia Mayor.

Desde sus origenes se diferencian en su estructura urbana dos áreas caracteristicas: un barrio de indios, actualmente barrio de pescadores, y un barrio de españoles, actual barrio de ganaderos con sus parroquias correspondientes: San Miguelito para los indios y La Candelaria para los blancos.

La característica dominante de su morfologia es la homogeneidad de la edificación, con estructuras porticadas de una planta, que utilizan el color de forma espectacular.

Los problemas más acuciantes que se reflejan en el Estudio del Centro Histórico pueden resumirse en los siguientes:

- Falta de incentivos económicos para poder permanecer viviendo en la población.

- Azolvamiento del río Papaloapan con fuerte pérdida de los recursos pesqueros que, actualmente, están

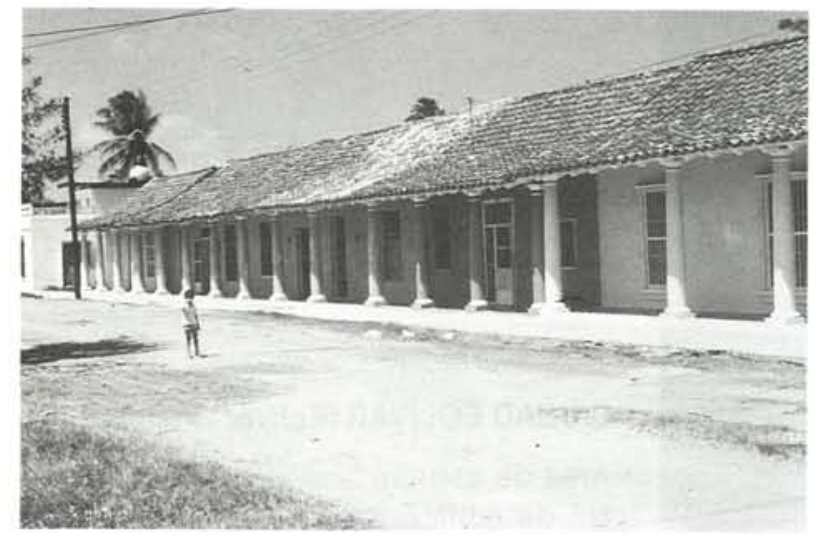

Edificación tradicional.

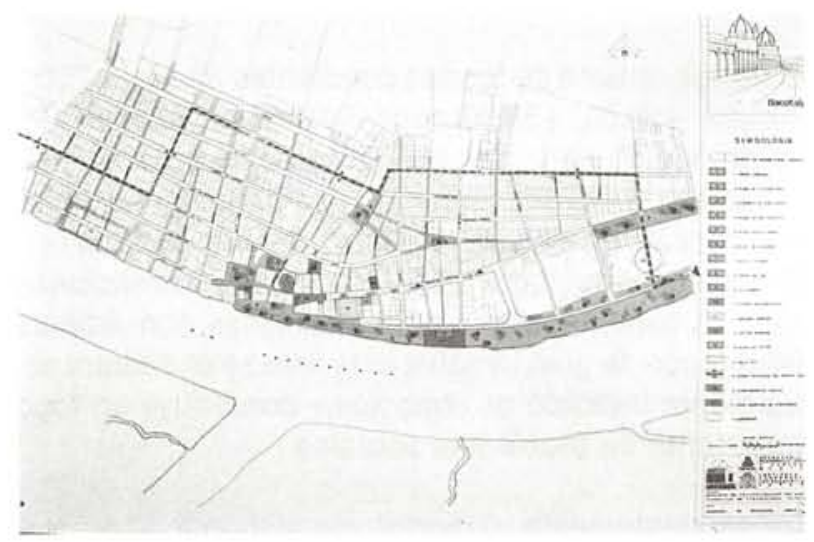

Propuestas de intervención.

(c) Consejo Superior de Investigaciones Científicas Licencia Creative Commons 3.0 España (by-nc) dando empleo al $47 \%$ de la población activa. Como consecuencia, se padecia una disminución importante de la capacidad vital de la estructura urbana, con abandono de los usos residenciales y del mantenimiento continuado de las edificaciones.

- Sustitución de la edificación tradicional por nuevas edificaciones mal incorporadas con tipologías y materiales ajenos a la morfología del centro, que se están implantando en la economía de Tlacotalpan, destrozando la base productiva regional e incorporando grandes áreas de pastos cegando las lagunas (de uso público) y concentrando, en poquísimas manos, extensas fincas ganaderas que destruyen un número importante de empleos.

El programa de Proyectos de Intervención propone:

- La recuperación de la relación de la población con el rio, a nivel de estructura urbana, mediante la crea. ción de un parque lineal, y la incorporación del muelle de pescadores al área libre.

- El desvío del tráfico pesado, que actualmente atraviesa el centro urbano, hacia el perímetro de la población.

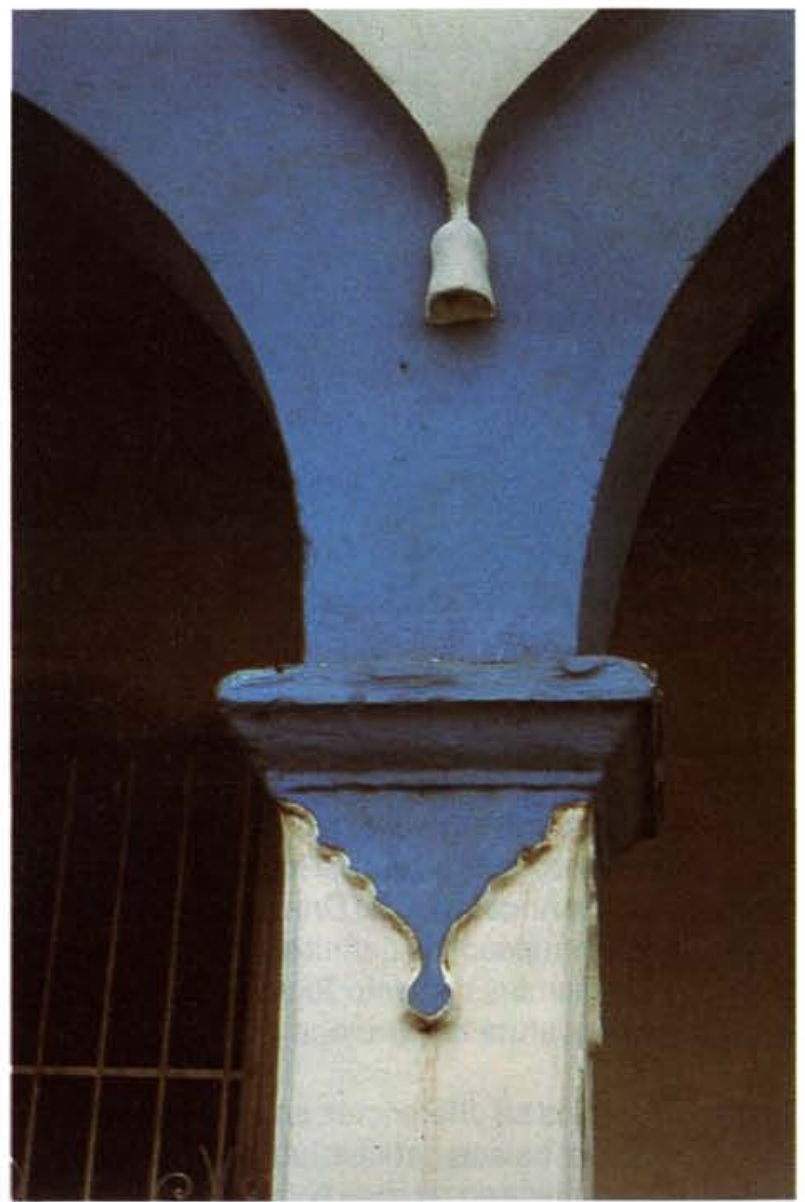

El color de la edifiación (detalle).

http://informesdelaconstruccion.revistas.csic.es 
- La recuperación de las siete plazas existentes, incluida la antigua alameda.

- La restauración del Teatro Municipal, y una serie de viviendas tradicionales, etcétera.

Desde que finalizó el Estudio de Revitalización en 1984, la falta de una contrapartida local, al no existir prácticamente presupuestos a nivel de todo el pais para obras de revitalización del Patrimonio y los continuos cambios en los responsables del área, tanto a nivel del Estado de Veracruz como nacional, han hecho imposible acometer el programa de obras con un mínimo de garantias.

Afortunadamente, en los últimos meses, la situación ha cambiado radicalmente y, en la actualidad, existe un
Instituto de Cultura Veracruzano, dependiente del Estado de Veracruz con fondos propios, que ha decidido retomar el tema de Tlacotalpan asumiendo las contrapartidas locales.

En este sentido y apoyando la tradición cultural del pueblo "jarocho" que, a pesar de las situaciones adversas, sigue manteniendo un profundo sentido de unión en torno a la cultura, música, danza, teatro, etc., y dentro de los proyectos previstos en el Programa de Revitalización, se propone acometer la restauración del Teatro Nezahualcoyolt, verdadero protagonista y punto de encuentro del pueblo de Tlacotalpan que, en la actualidad, y a pesar del lamentable estado de ruina en que se encuentra, sigue utilizándolo contra viento y marea.

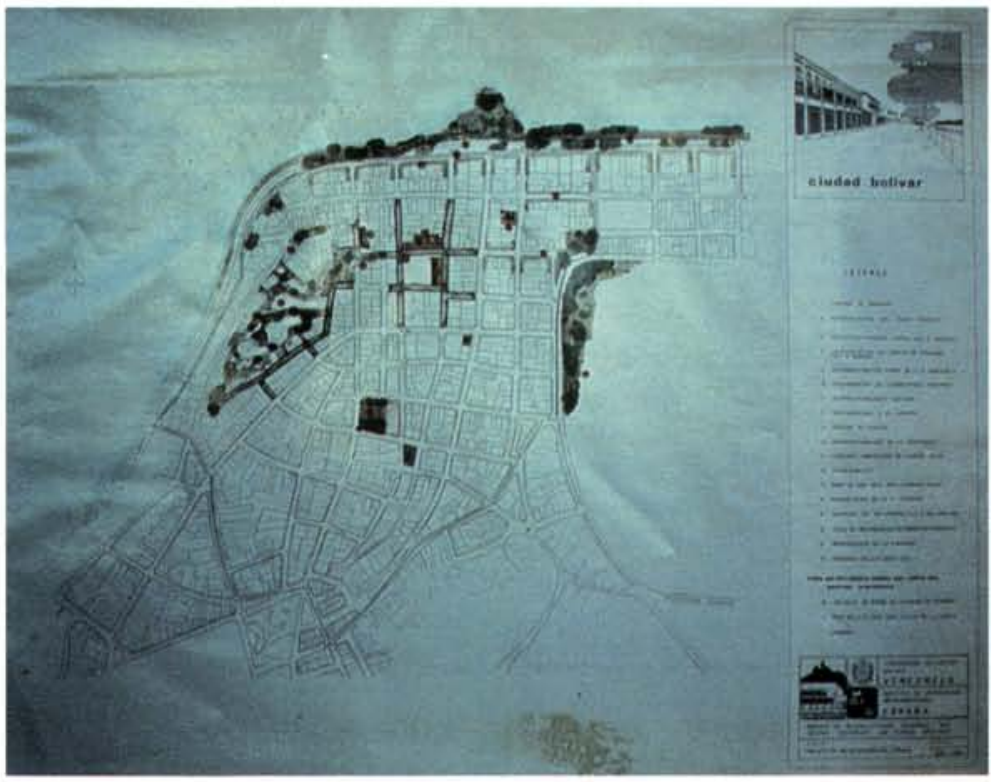

Propuestas de intervención

\section{CIUDAD BOLIVAR (Bolivar · Venezuela):}

Área de estudio $67,12 \mathrm{Ha}$

N. ${ }^{\circ}$ de edificaciones 1.208

N. ${ }^{\circ}$ de habitantes 4.864

Densidad de población .. 114,5 Hab/Ha
Ciudad Bolivar se funda el 21 de diciembre de 1595 con el nombre de Santo Tomé de Guayana, se traslada seis veces de emplazamiento por el acoso de piratas ingleses y holandeses hasta su actual localización, 100 km río arriba en "La Angostura del Orinoco", sobre el "Cerro del Vigía", instalándose definitivamente en febrero de 1764 con el nombre de Santo Tomé de la Nueva Guayana, en la angostura del Orinoco.

Desde sus inicios se diferencian en su estructura original tres áreas características: un área plana (cota $+19,00$ ) desarrollada en retícula sobre dos calles paralelas a la ribera del río Orinoco, dando servicio al puer- to fluvial; un área de fuertes pendientes (cotas $+21,00$, $+41,00,+55,00,+59,00$ ) consolidándose sobre el " $\mathrm{Ce}$ rro del Vigía", en la que las calles adaptan la retícula forźandola sobre acusadísimas pendientes; $y$ un tercer área natural, en torno al "Zanjón", de más de $5 \mathrm{Ha}$ con 20 m de desnivel $(\operatorname{cota}+39,00,+20,00)$ y formaciones rocosas espectaculares entremezcladas con árboles autóctonos de gran tamaño; este área se encuentra actualmente invadido de chabolas y constituye un foco importante de problemas sociales.

Consecuentemente su morfología responde a tres realidades bien diferenciadas: De una parte la zona de las 


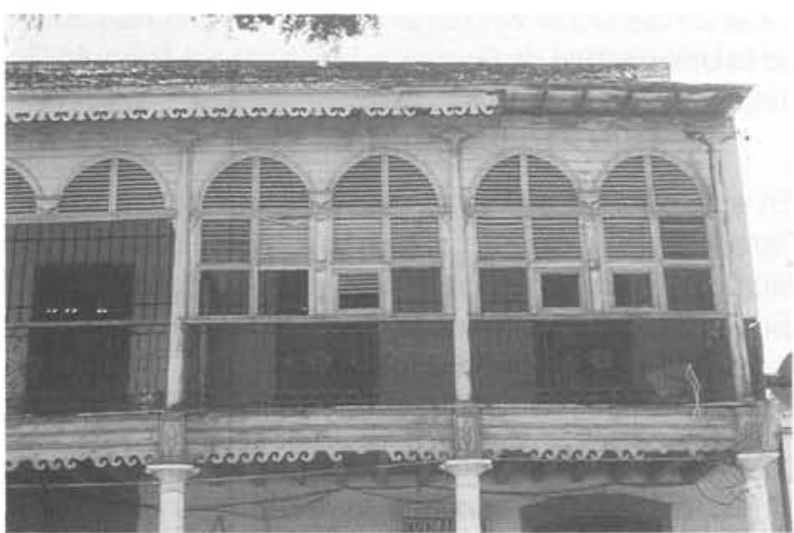

Galerias del Paseo Orinoco.

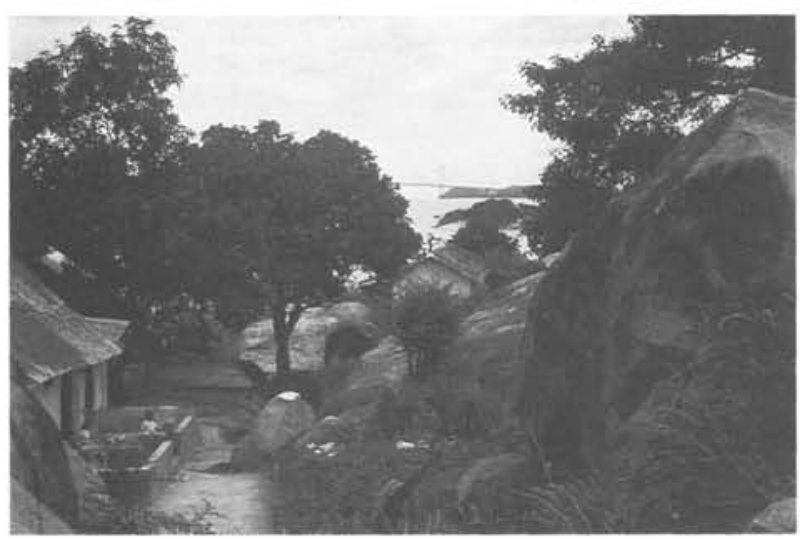

Parque del Zanjón.

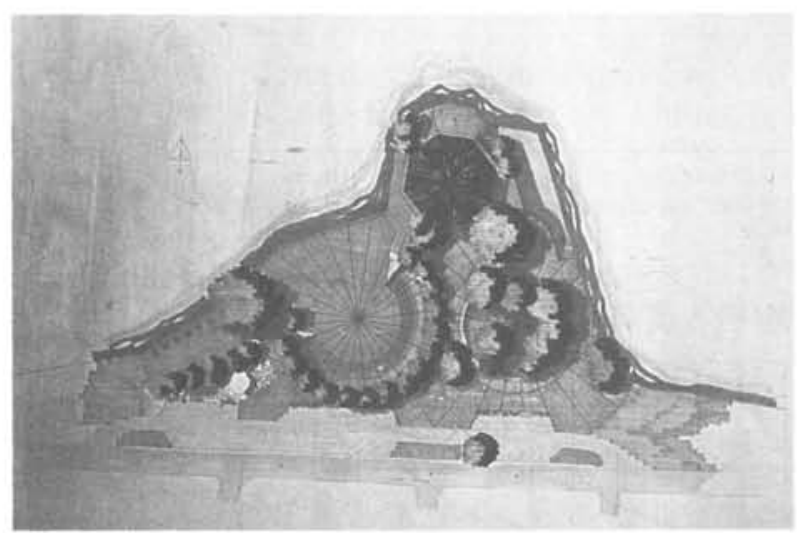

Proyecto del Parque "El Mirador".

galerías (ribera del río) con una arquitectura porticada en dos niveles, con galería superior y clarísimas influencias antillanas (el puerto fluvial proporcionaba excelentes relaciones ultramarinas). La zona de la colina, o zona de residencias, con una arquitectura de fuerte influencia española con edificaciones de mampostería de una planta, desarrolladas en torno a patios y grandes y ritmicas ventanas enrejadas en las fachadas. $Y$ El Zanjón que, por su particular identidad, constituye una unidad morfológica irrepetible.

El diagnóstico de la situación tanto física como socio-

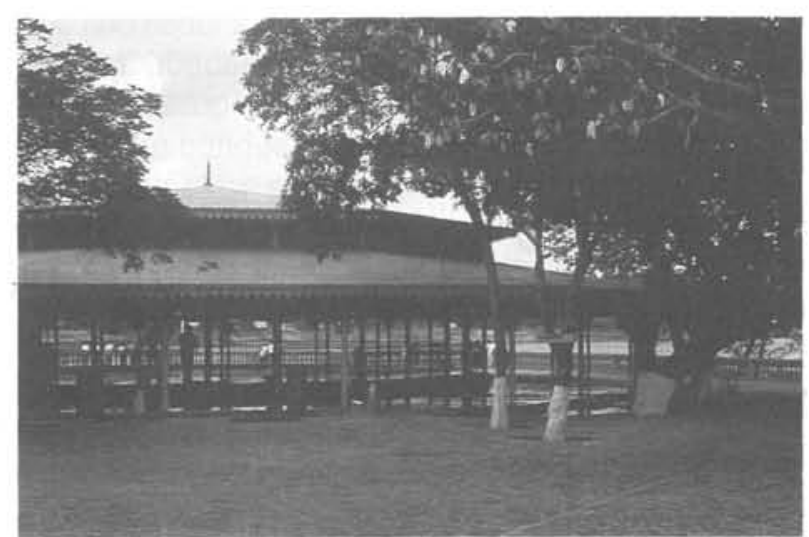

Parque "El Mirador" después de la intervención, 1989.
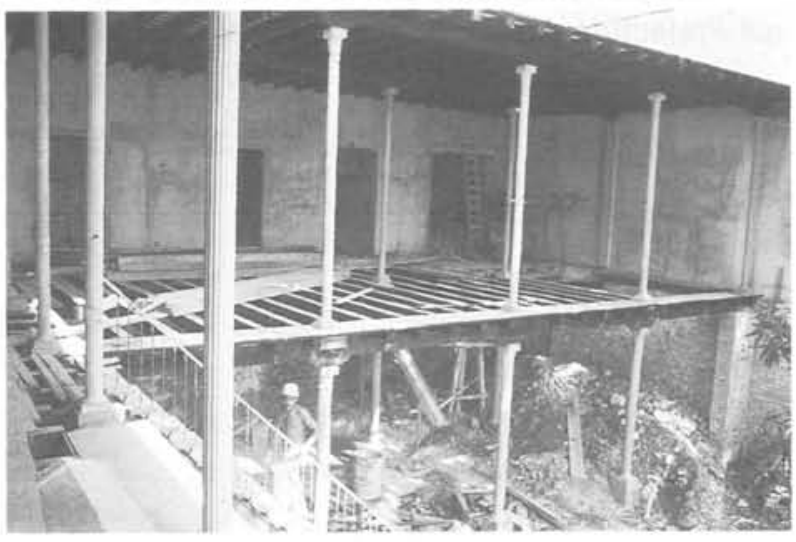

Biblioteca Pública, intervención 1988.

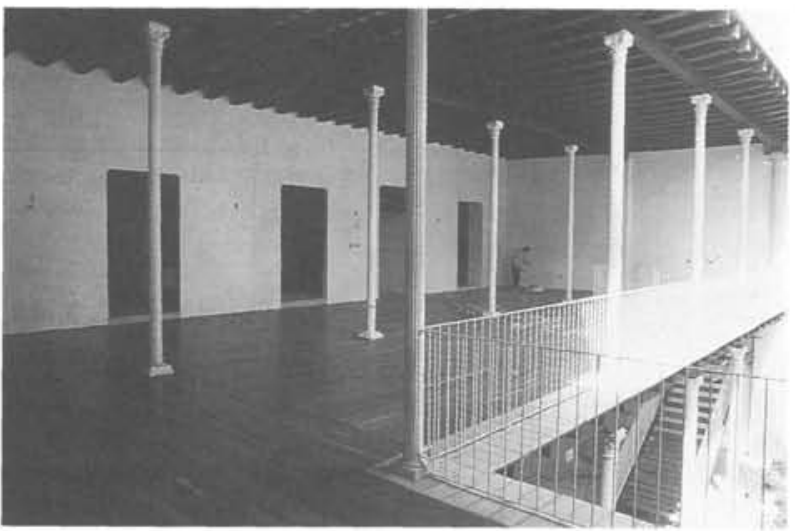

Biblioteca Pública después de la intervención, 1989.

económica nos lleva a la formulación de un programa de proyectos de intervención y de incentivos sociales, entre los que destacan: la recuperación del área del mirador en el Paseo Orinoco (antigua zona del puerto), la recuperación del área natural de "El Zanjón" como parque urbano, la promoción de un programa de viviendas sociales para realojar a las familias que salen de las chabolas de "El Zanjón" en solares próximos dentro del Centro Histórico, la recuperación de las edificaciones con galerias, la negociación de créditos preferenciales para los residentes a través del I.N.A.V.I., aplicables a la rehabilitación de viviendas. 
El Programa de Proyectos viene cumpliéndose con adelanto desde el año 1987, habiéndose inaugurado el pasado mes de enero: "El Mirador de Angostura", regenerándose como área libre de uso público un área de $1,6 \mathrm{Ha}$., en una zona privilegiada a la orilla del río Orinoco que, hasta el proyecto de revitalización, era una zona confusa, invadida y sucia, inútil para el uso comunitario. El Comedor Social, revitalizándose una antigua casa "guayanesa" situada en pleno centro, magníficamente comunicada y salvada "in extremis" de la piqueta. La primera fase de una serie de viviendas sociales donde deberán irse realojando las familias que viven actualmente en "ranchitos" invadiendo el área natural del Zanjón. La escalinata, la Plaza Miranda, contemplada conjuntamente con la revitalización de la actual Prefectura como Teatro Municipal (obra 1989), la
Casa de las Doce Ventanas como sede del Rectorado de la Universidad de Guayana, la Biblioteca Rómulo Gallegos, etcétera.

En el Programa de Obras del 89 deberá finalizarse: e! Parque de "El Zanjón" y acometerse el futuro Teatro Municipal. El Hospital de Niños, primer dispensario mé. dico de la Seguridad Social. En el área central, las Ga. lerías del Paseo Orinoco, etcétera.

Las normas de protección, convertidas en ordenanza municipal desde el año 1987, están siendo puestas en aplicación escrupulosamente, proporcionándose a los ciudadanos todo tipo de ayuda desde la Oficina del Centro Histórico.

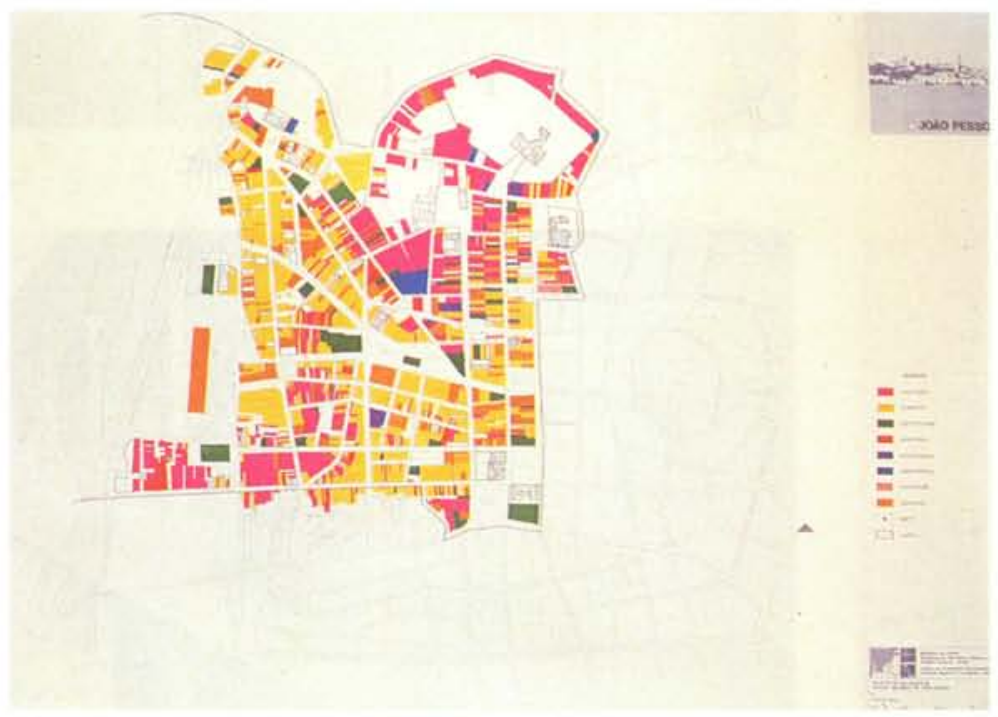

Usos del suelo.

\section{JOÃO PESSOA (Paraiba - Brasil)}

Área de estudio $117,00 \mathrm{Ha}$ N. ${ }^{\circ}$ de edificaciones ................... 2.179 $\mathrm{N} .^{\circ}$ de habitantes ....................... 3.660 Densidad de población ...... $28 \mathrm{Hab} / \mathrm{Ha}$
La ciudad de João Pessoa se fundó en 1583 con el nombre de "Philipe a de Nuestra Señora de las Nieves" en honor de Felipe II.

Desde sus inicios se establecen en su estructura urbana dos áreas caracteristicas: la Ciudad Baja junto a un puerto fluvial en la margen del río Sanhagua (cota $+3,00 \mathrm{~m}$ ), donde se concentran las actividades comerciales e industriales; y la Ciudad Alta (cota $+45,00)$, zona residencial de dos manzanas de ancho por nueve de largo, ocupando la meseta del cerro y rellenando el espacio urbano a los lados de dos ejes religiosos que forman una cruz latina: San Francisco y los Jesuitas en el eje mayor, y El Carmen y San Benito en el menor.
Estas dos zonas se unieron siempre por dos senderos que, con el tiempo, pasaron a ser calles del Centro Histórico, la ladera de San Francisco y sobre todo la actual "Rua Da Areia", eje diagonal de unión de los dos núcleos de actividad.

La gravisima situación de degradación urbana y la práctica despoblación residencial que padece actualmente el Centro Histórico, casi ha conseguido destruir la morfologia original del área; no obstante la persistencia de la traza primitiva (calles y plazas) y la fuerza e importancia de los edificios singulares han mantenido una cierta unidad en las "dos" ciudades, la baja y la alta, $y$ han conseguido algún respeto por la edifica- 


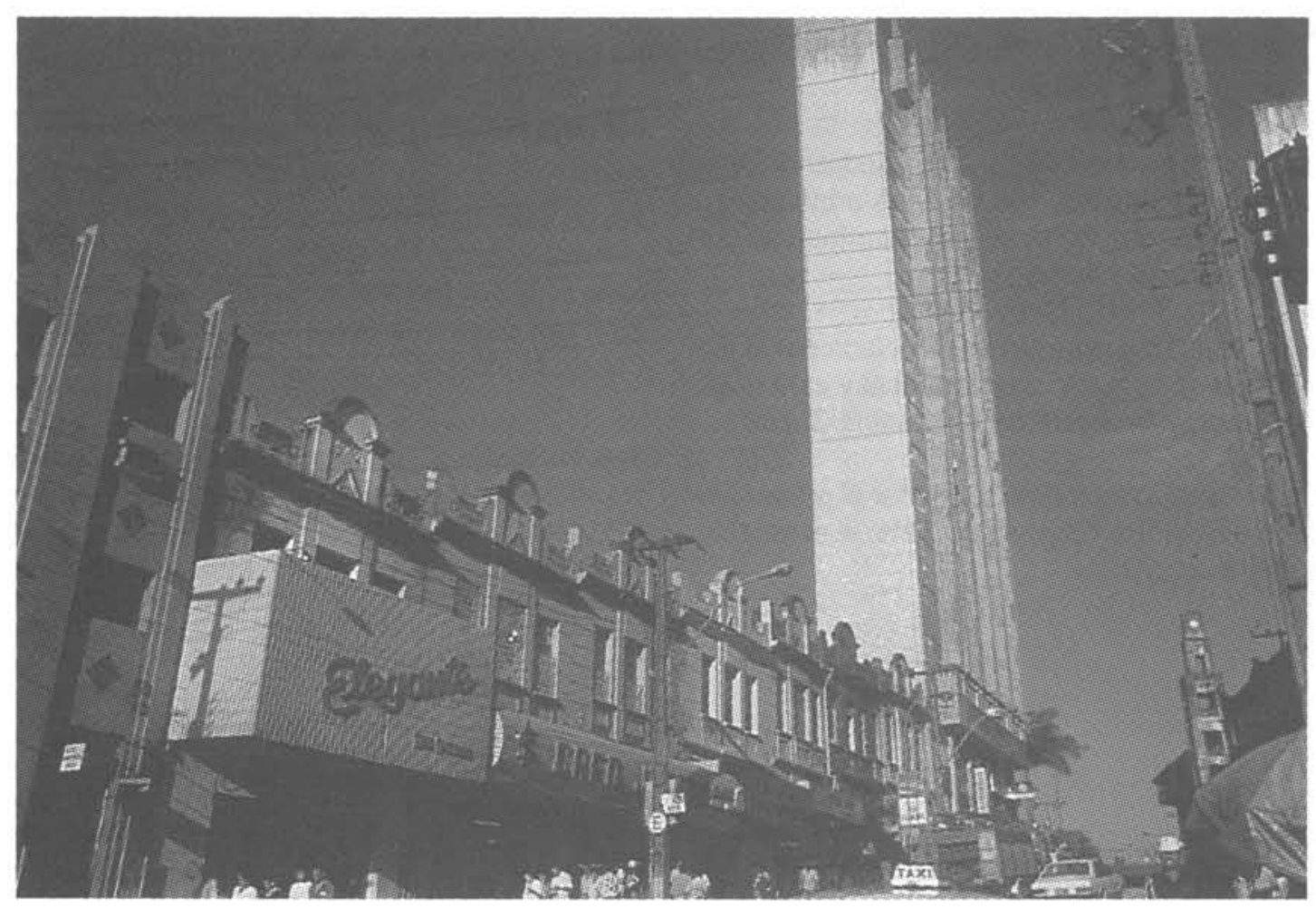

Agresiones en el Centro Histórico.

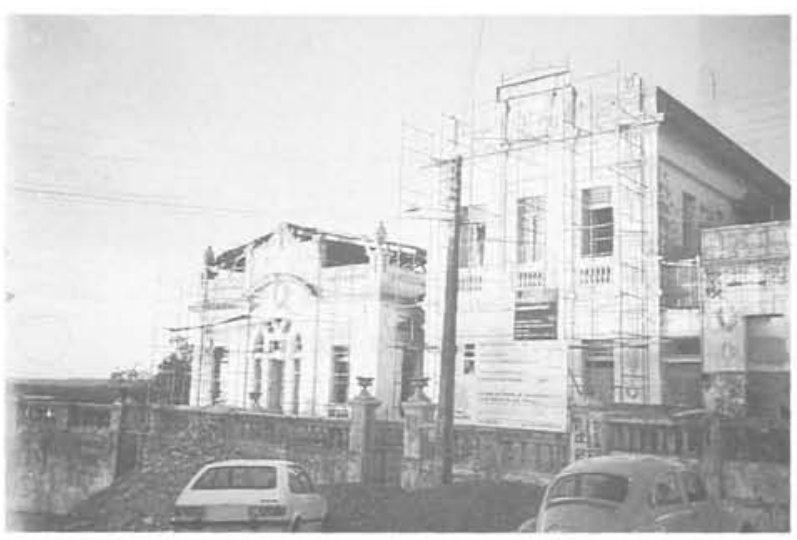

Obras de intervención 1988: "Hotel Globo".

ción residencial que los rodea y que aún se mantiene dentro de las caracteristicas tradicionales del XIX. Es sintomático destacar que en todo el Centro Histórico sólo permanece una edificación residencial del siglo XVIII.

El programa de proyectos y propuestas pretende recuperar esos dos núcleos originales de valor entendidos como secuencias urbanas, a partir de las cuales se pue. da conseguir la recuperación del tejido urbano mediante la revalorización de los espacios públicos con nuevos proyectos de ordenación de las plazas de "El Carmen", "San Francisco", la Catedral y la calle General Osorio en la Ciudad Alta, y los edificios de valor cir-

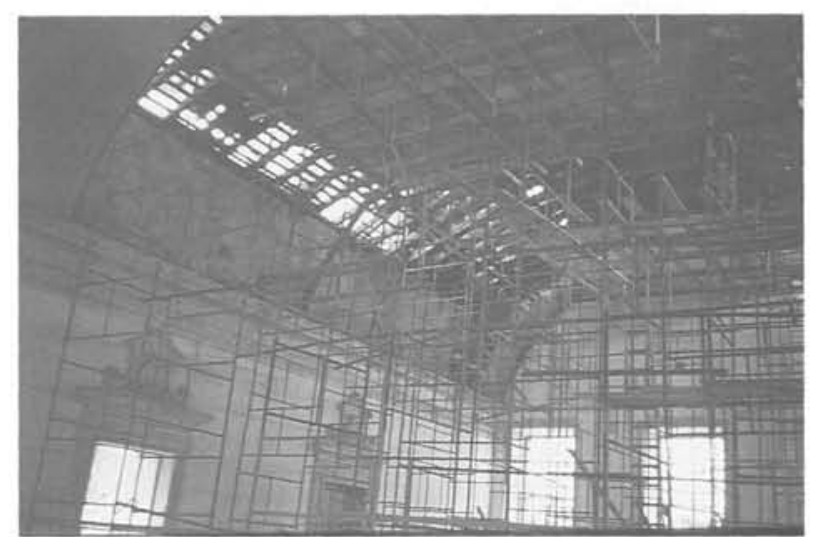

Obras de intervención 1988: "Iglesia San Bento".

cundantes, conventos de "El Carmen", "San Francisco" y San Benito incorporándolos, una vez restaurados, a usos sociales comunitarios (sala de conciertos, archivo, Museo Diocesano, etc.), también en la Ciudad Alta. Las Plazas Antenor Navarro y San Pedro con los edificios circundantes y el "Hotel Globo", que será recuperado como Secretaría de Turismo, en la Ciudad Baja.

Las obras, iniciadas en 1988, están suponiendo un verdadero proceso de regeneración urbana. Actualmente se encuentra concluida la Plaza de San Francisco y "El Carmen", en la Ciudad Alta y, para mediados de este año, estarán listas la Iglesia de San Bento revitalizada 
para sala de conciertos y auditorio, y el "Hotel Globo", donde quedará instalada la Oficina del Centro Histórico y la Secretaria de Turismo.

El Programa de Obras del 89 continúa apoyando la recuperación de los dos núcleos urbanos principales a partir de las obras ya concluidas para continuar el proceso de revitalización homogénea.

La Casa de los Azulejos ha sido expropiada por el Gobierno del Estado como aportación local y será destinada a la "Legión Brasilera de Asistencia Social".

El Huerto de San Francisco va a suponer el primer parque urbano del Centro con más de $7 \mathrm{Ha}$ de extensión, profusamente arborizada.
Con la reestructuración de las fachadas de unión de las dos plazas, ya recuperadas, se pretende generar un ejemplo demostrativo de lo que se puede y se debe hacer para recuperar la calidad de vida del área central.

Por su parte, la eliminación del surtidor de gasolina de la Plaza Antenor Navarro, que ha venido negociándose todo el año anterior con los concesionarios, va a permitir recuperar uno de los espacios más hermosos del Centro Histórico.

Paralelamente al Programa de Obras, la Oficina del Centro Histórico viene funcionando desde hace año y medio, prestando asistencia técnica a los ciudadanos y controlando la aplicación de las normas de protección.

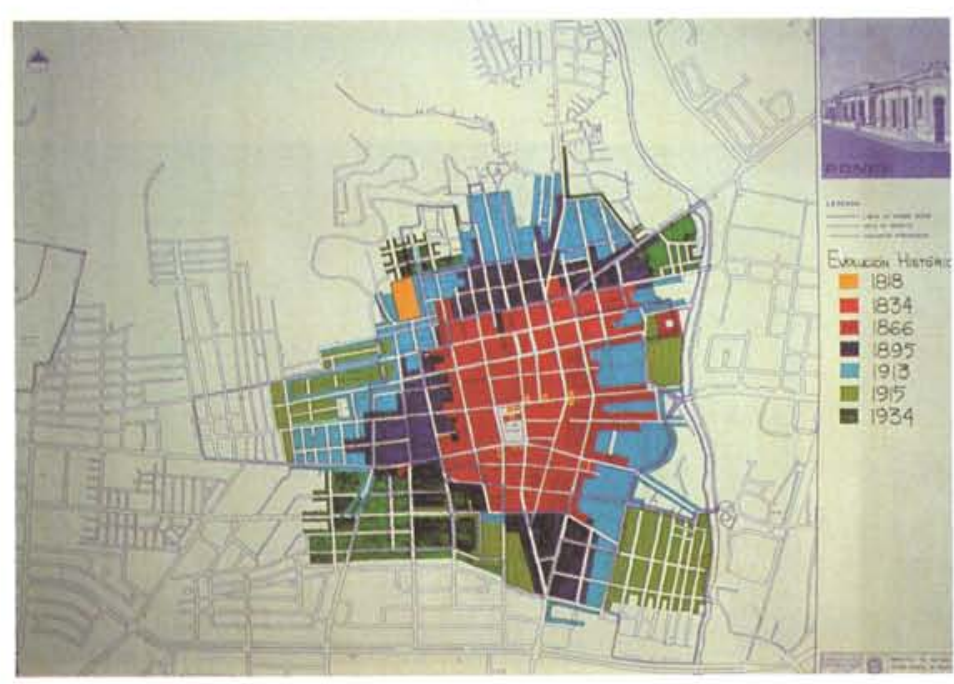

Evolución Histórica.

PONCE (Puerto Rico)
Área de estudio .................. $73,81 \mathrm{Ha}$
N. ${ }^{\circ}$ de edificaciones .............. 935
N. ${ }^{\circ}$ de habitantes .................. 2.068
Densidad de población .. $34,77 \mathrm{Hab} / \mathrm{Ha}$

La ciudad de Ponce está localizada en el sur de Puerto Rico, estratégicamente aislada de San Juan por la Cordillera Central que divide la isla longitudinalmente en "norte" y "sur".

Esta división geográfica ha sido a lo largo de su historia mucho más que una barrera física, pudiendo hablarse hasta el dia de hoy del "mundo del norte", capitalino, desarrollado y oficial, y el "mundo del sur", desafiante, conflictivo y con graves problemas económicos.

Ponce comienza siendo un hato ganadero, convirtiéndose pronto en un poblado de comerciantes y contrabandistas, gracias a su puerto natural estratégicamente localizado frente a las costas del Caribe peninsular.
La ciudad se desarrolla a $2 \mathrm{~km}$ de la costa paralelamente con el asentamiento del puerto, "la playa", produciéndose su apogeo a lo largo del siglo XIX, pasando de pueblo a villa y ciudad en menos de cincuenta años.

Su existencia, vitalidad y decadencia están ligadas a los ciclos económicos de la caña de azúcar y el café, convirtiéndose en uno de los mayores centros exportadores del Caribe en el siglo XIX.

Su aislamiento geográfico, su pujanza económica y sus inquietudes politicas y culturales la convirtieron en la auténtica capital de Puerto Rico a finales del siglo pasado. 


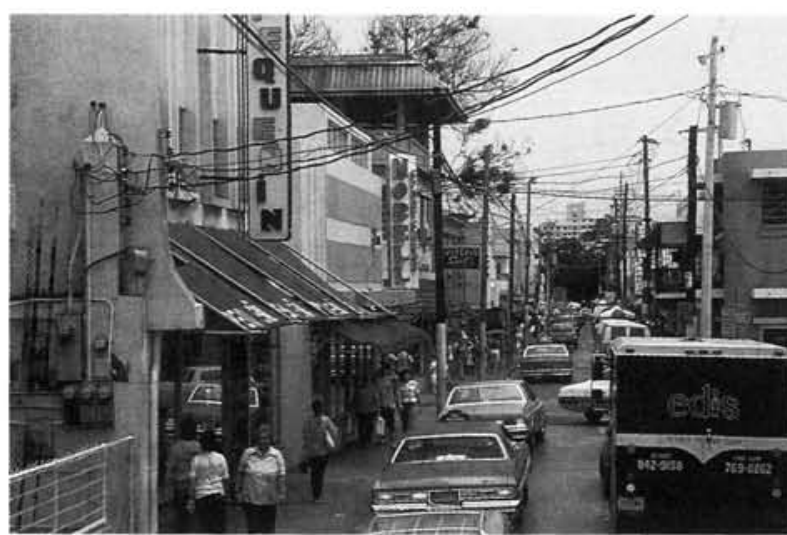

Calle Comercio, situación actual.

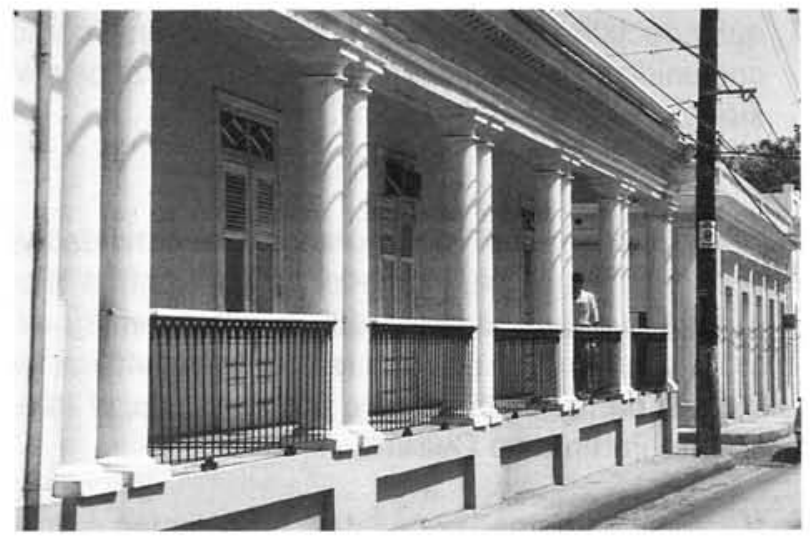

Tipologia de la edificación.

Ponce se desarrolla desde sus inicios en torno a la plaza principal estableciéndose, en su morfología, una clara relación entre importancia y singularidad de la edificación y proximidad a la plaza.

Sus tipologías responden a influencias caribeñas, "intelectualizadas" por la relación internacional subsiguiente de su actividad como núcleo exportador, con un elemento característico y casi propio, la galería exterior de madera elevada sobre un zócalo.

En la actualidad y debido al fortisimo problema de depresión económica derivado de las crisis sucesivas, se observa en el Centro Histórico un profundo y peligroso proceso de sustitución de la edificación tradicional con invasiones indiscriminadas de los usos comerciales que práctiamente han desplazado los residentes estables y permanentes.

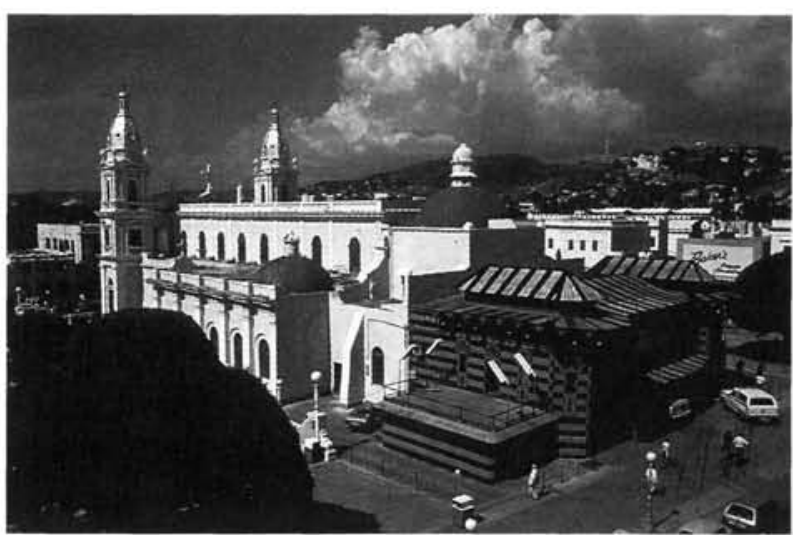

Espacio urbano: Plaza de las Delicias.

El Programa de Proyectos y Propuestas pretende, fundamentalmente, recuperar los usos de vivienda y dotar al área central de los equipamientos comunitarios que contribuyan a su atractivo como zona residencial; en ese sentido, se propone convertir la ribera del rio Portugués en un parque lineal, recuperar el solar del antiguo Hospital de Damas (demolido con fines especulativos) como futuro Parque de La Marina, la recuperación de una serie de residencias tradicionales como la Casa "Farinachi", la Casa "Villaronga", la Casa "Saurí", el Mercado de los Perros, etc., conjuntamente con un programa peatonal y reordenación del tránsito coordinado con el plan "Ponce en Marcha".

Por otra parte, el Estudio de Revitalización ha dado los primeros frutos positivos, ya que el pasado mes de noviembre se aprobó, por el Instituto de Cultura de Puerto Rico y la Junta de Planificación, la extensión del área considerada como Centro Histórico de Ponce, abarcando, en la actualidad, más de 70 Ha y 1.200 edificaciones, frente a las 256 consideradas en forma dispersa en la declaratoria de 1967.

Apoyando esta actitud positiva hacia el proyecto, la Junta de Planificación viene estudiando una fórmula de incorporar el Reglamento de Protección de Ponce a la totalidad de la isla como reglamento de la propia Junta, estando lista prácticamente la propuesta de incorporación.

Asimismo, y al igual que en el resto de los Estudios de Revitalización, se ha creado una Oficina de Centro Histórico para la que, desde el primer momento, se es. tá gestionando el Proyecto de Revitalización.

\section{ACTUACIONES 1989}

En 1989 se están desarrollando los Estudios de Revitalización de los Centros Históricos de San Juan de Puerto Rico y Quito (Ecuador).
Se han firmado los correspondientes convenios con el Instituto Puertorriqueño de Cultura y la Municipalidad de Quito, respectivamente. 
En el caso de Quito, por tratarse de un Centro Histórico de una considerable extensión (probablemente el mayor de América), y la complejidad de su problemáti$\mathrm{ca}$, exige que la realización del estudio se prolongue por dos años.

El equipo redactor es el de mayor número de expertos, y se cuenta con la asesoría técnica especializada para temas concretos (transportes, circulación, etcétera).

Asimismo, va a iniciarse en julio de 1989 el estudio del Barrio Reus Norte de Montevideo, con un equipo de seis expertos locales, durante seis meses.

\section{CONCLUSIONES}

Las experiencias desarrolladas hasta el momento nos han permitido llegar a una serie de conclusiones que afectan, prácticamente sin distinción, a los casos estudiados y que podrían ser considerados como "problemas generales":

1) Falta de definición y criterios en la delimitación de los Centros Históricos objeto de estudio.

La situación más frecuente es encontrarnos "Perímetros Oficiales" a los que les afecta la calificación de Centros Históricos, que no responden a ningún criterio morfológico concreto, y que, o bien son el resultado de ir "envolviendo" edificaciones aisladas por una línea imaginaria, o abarcan áreas extensisimas sin ninguna identidad.

El caso de Ciudad Bolivar con un decreto nacional parcial y un decreto regional mucho más amplio, 0 el caso de João Pessoa con un perimetro del Instituto de Cultura de la Paraiba de más de $300 \mathrm{Ha}$ que no tienen nada que ver con la auténtica extensión del Centro Histórico que es la tercera parte, o el caso de Ponce en el que por el contrario el área delimitada como Centro Histórico por el Instituto de Cultura de Puerto Rico es una figura caprichosa que no se identifica para nada con la morfología urbana.

2) Multiplicación de instituciones con las mismas competencias sobre las áreas históricas, prácticamente enfrentadas entre si y sin la menor coordinación a la hora de intervenir... (Juntas Nacionales de $\mathrm{Pa}$ - trimonio, Ministerios de Cultura, Gobernaciones de los Estados, Direcciones de Patrimonio, Juntas de Planeamiento...)

3) Poblaciones ajenas desde siempre a la supervivencia de sus Centros Históricos, marginadas de cualquier decisión que les afecte, sin organizarse como comunidad, y, consecuentemente, sin "fuerza de presión".

4) "Grupos de interés" incorporados a las actividades económicas que se implantan en los Centros Históricos que utilizan la estructura urbana en su exclusivo beneficio y que ignoran por completo los intereses de la colectividad y, por supuesto, el interés del Patrimonio Cultural.

Manejan "criterios" populistas, representan números de votos "considerables" y son infractores habituales de las más elementales normas de convivencia (comerciantes, constructores, contratistas, etcétera).

5) Poblaciones con graves problemas de recesión económica, motivadas, en su mayoria, por decisiones políticas de carácter "centralista" que han desestabilizado todas las economías locales:

\section{Tlacotalpan:}

Puerto fluvial; construcción del ferrocarril del itsmo; Puente sobre el Papaloapan, azolvamiento del río (no se draga deliberadamente).

\section{Ciudad Bolivar:}

Creación de la ciudad de Puerto Ordaz a $80 \mathrm{~km}$ de Ciudad Bolívar (1950) Concentración de la industria, los altos hornos, la construcción y el poder económico (C.V.G.) (Presa del Guri).

\section{João Pessoa:}

Presión de Recife, desarrollo turístico e industrial paralelo en competencia. Presión de la ciudad de Campina (industria, mineria, etc.) "El negocio de la seca" (corrupción política y social).

\section{Ponce:}

Crisis del azúcar, crisis del café (monocultivos), crisis del petróleo (subida de los precios y caida de las 
petroquímicas), indice "oficial" de desempleo en 1975: $40 \%$ en la región sur.

6) Falta de incentivos económicos a la rehabilitación de las edificaciones residenciales particulares, lo que supone cargar sobre los propietarios la responsabilidad del mantenimiento del patrimonio de los Centros Históricos sin ayuda de ningún tipo. (Créditos preferenciales, exenciones de impuestos, etcétera).

7) Impunidad de los infractores de los reglamentos municipales que en la mayoría de los casos demuelen, modifican, alteran, construyen, etc., sin el control ni la presión de ninguna autoridad municipal, estatal o nacional.

Finalmente, es importante destacar que los proyectos de revitalización realizados hasta la fecha han revertido realmente estos procesos negativos pudiendo afirmarse que han supuesto una auténtica frontera entre la degradación, el abandono y la anarquia en que se encontraban antes y la situación de franca recuperación en que se encuentran "después".

\section{publicación del ICCET/CSIC}

\section{ACUEDUCTOS ROMANOS EN ESPAÑA \\ Carlos Fernández Casado}

Prof. Dr. Ing. de Caminos, Canales y Puertos

Esta publicación se compone de una serie de articulos, publicados en la Revista "Informes de la Construcción", en los cuales se hace un análisis de los acueductos romanos que existen en España y el balance de las condiciones de conservación en que se encuentra cada uno de ellos, incluyendo referencias históricas y literarias.

Se ha ilustrado con la reproducción de la valiosa documentación gráfica que posee el prestigioso autor.

Un volumen encuadernado en couché, a dos colores, de $21 \times 27$ centimetros, compuesto de 238 páginas, numerosos grabados, dibujos, fotos en blanco y negro y figuras de linea.

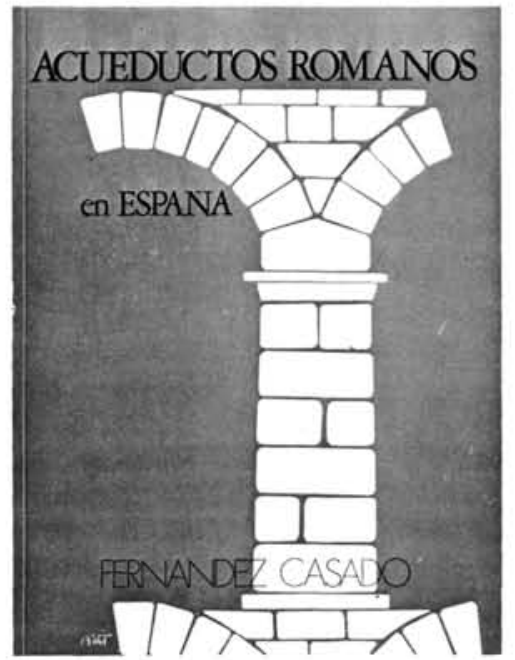

Precio: España, 1.500 ptas., 21 \$ USA. 